\title{
Infrared Imaging Results of an Excited Planar Jêt
}

NREL/TP--254-4515

DE92 001185

Robert B. Farrington

Prepared for the ASME International

Solar Energy Conference, Maui, Hawaii, April 4-8, 1992

National Renewable Energy Laboratory (formerly the Solar Energy Research Institute) 1617 Cole Boulevard Golden, Colorado 80401-3393

A Division of Midwest Research Institute Operated for the U.S. Department of Energy under Contract No. DE-AC02-83CH10093

December 1991 
On September 16, 1991, the Solar Energy Research Instltute was designated a natlonal laboratory, and Its name was changed
to the Natlona! Renewable Energy Laboratory.

\section{NOTICE}

This report was prepared as an account of work sponsored by an ageicy of the United States government. Neither the United States government nor any agency thereof, nor any of their employees, makes any warranty, express or implied, or assumies any legal liability or responsibility for the accuracy, completeness, or usefulness of any information, apparatus, product, or process disclosed, or represents that its use would not infringe privately owned rights. Reference herein to any specific commercial product, process, or service by trade name, trademark, manufacturer, or otherwise does not necessarily constitute or imply its endorsement, recommendation, or favoring by the United States government or any agency thereof. The views and opinions of auithors expressed herein do not necessarily state or reflect those of the United States government or any agency thereof.

Printed in the United States of America

Available from:

National Technical Information Service

U.S. Department of Commerce

5285 Port Royal Road

Springfield, VA 22161

Price: Microfiche A01

Printed Copy A02

Codes are used for pricing all publications. The code is determined by the number of pages in the publication. Information pertaining to the pricing codes can be found in the current issue of the following publications which are generally available in most libraries: Energy Research Abstracts (ERA); Govern. ment Reports Announcements and Index (GRA and 1); Scientific and Technical Abstract Reports (STAR); and publication NTIS-PR-360 available from NTIS at the above address. 


\title{
INIFRARED IMAGING RESULTS OF \\ AN EXCITED PLANAR JET
}

\author{
Robert B. Farrington \\ National Renewable Energy Laboratory \\ 1617 Cole Blvd. \\ Golden, CO 80401
}

\section{ABSTRACT}

Planar jets are used for many applications including heating, cooling, and ventilation. Generally such a jet is designed to provide good mixing within an enclosure. In building applications, the jet provides both thermal comfon and adequate indoor air quality. Increased mixing rates may lead to lower short-circuiting of conditioned air, elimination of dead zones within the occupied zone, reduced energy costs, increased occupant comfort, and higher indoor air quality.

This paper discusses using an infrared imaging system to show the effect of excitation of a jet on the spread angle and on the jet mixing efficiency.

Infrared imaging captures a large number of data points in real time (over 50,000 data points per image) providing significant advantages over single-point measurements. We used a screen mesh with a time constant of approximately 0.3 seconds as a target for the infrared camera to detect temperature variations in the jet.

The infiared images show increased jet spread due to excitation of the jet. Digital data reduction and analysis show changes in jet isotherms and quancify the increased mixing causad by excitation.

\section{INTRODUCTION}

The rate of outside air delivery needed in an enclosed room has been investigated since 1836 when Tredgold determined that Welsit miners required about 1.9 liters/second/person ( $\mathrm{L} / \mathrm{s} /$ person) (4 cubic feud minute/person [cfm/person]) of outside air to work safely'. When the American Society of Heating and Ventilating Engineers (ASHVE) forme. in 1894, it recommended an outside air rate of $16.5 \mathrm{~L} / \mathrm{s} /$ person (3!: $\mathrm{cfm} /$ person), which accounted for the lifestyle of that time (gaslights cooking fires, personal hygiene). As technology progressed, the rate dropped to $4.7 \mathrm{~L} / \mathrm{s}$ person (10 cfm/person) as recommended by Yaglou in 1936 in cases where people were the main pollutant source. This level was adopted by the American Standards Association (ASA) in 1946 (ASA, 1946). ASA became the American National Standards Institute (ANSI), and ASHVE hecame the American Society of Heating. Refrigerating, and Air-Conditioning Engineers (ASHRAE). ASHRAE (1973) re:ommended $4.7 \mathrm{Ls} /$ person ( $10 \mathrm{cfm} /$ person) as the rate of outside air but now allowed the minimum recuired rate to drop (o) $2.4 \mathrm{~L} / \mathrm{s} /$ person (5 cfm/person) partially in response to the energy crisis of the 197(). Later, the ASHRAE (1981) standard was modified such that 2.4 $\mathrm{U} / \mathrm{person}$ ( $5 \mathrm{cfm} /$ person) wiss the minimum rale only where smoking

I See McNall (1988) for an overview of the history of recommended minimum ventilation rates. was not permitted, and $9.4 \mathrm{~L} / \mathrm{s} /$ person $(20 \mathrm{~cm} /$ person) was required where smoking was permitted. Designers were to choose one of the two values for sizing ventilation systems. Designers had a tendency to chose the lower ventilation rate regardless of the future use of the building Lower minimum ventilation rates led to increased occupant complaints about indoor air quality. The causes of these complaints have been the subject of many conferences sponsored by such organizations as the National Science Foundatios (University of Illinois, 1988), the American Society for Testing and Materials (ASTM, 1989), the Electric Power Research Institure (EPRI, 1990), and ASHRAE (ASHRAE, 1991). Responding to concern over adequate fresh air delivered to building occupants, ASHRAE (1989) increased the minimum ventilation rate to $7.1 \mathrm{~L} / \mathrm{s} /$ person ( $15 \mathrm{cfm} /$ person) for general buildings and to $9.4 \mathrm{~L} / \mathrm{s} /$ person (20 $\mathrm{cfm} /$ person) for office buildings.

The cause and control of indoor air pollution has heen the subjett of considerable debate. Pollutant sources may he point sources, such as a copying machine, and can have local exhausts. However, many pollutant sources are dispersed, such as carpets, partitions, and building materials. Minimizing pollutants by proper selection of materials and adhesives is necessary hut may not he sufficient. Adequate exhausting of the pollutants is necessary and is accomplished by diluting the pollutants with outside air (presuming that the outside air is less polluted than the inside air). To do this efficiently, the outside air must be properly distributed. Previous research with scale modeling has shown that ventilation systems may short-circuit the supply air to the return duct. causing stagnant zones to form in the occupied zone (Farrington, 1990).

In addition to indoor air quality and energ,y efficiency, occupant comfort and productivity are also imporant concerns. The cost per employee is ahout 100 times greater than the energy cost on a :yuare-f(x)t hasis. Hence, if reducing energy costs by $20 \%$ decreases productivity by $1 \%$, then the value of the lost productivity is five times greater than the energy savings! Productivity is related to occupant comfort, which has heen linked to the effective draft temperature (Koestel, 1955), and expressed as a comfort equation (Fanger, 1988), and as the Air Diffusion Performance Index (Miller, 1979). A properly designed ventilation system must consider energy efficiency, indoor air quality, and occupant comfort.

This paper discusses using an infrared imaging system to show the effect of excitation of a jet on the spread angle and on the jet mixing efficiency. A jet with an increased spreading rate should lead to better room air distribution, enhanced dilution and removal of contaminants, and sufficiently low jet velocities to ensure occupant comfort. It addresses the issues of energy efficiency, indoor air quality, and occupant comfon. 


\section{HISTORY OF EXCITED JETS}

The excitation of jets was first reported by LeConte (1858) when he observed the effect of acoustical tones from a musical trio on gas lights while at a dinner party. Shortly after that Tyndall (1867) performed a series of experiments revealing bifurcation and trifurcation of acoustically excited jets, which have continued to be the subjects of recent investigations (Reynolds, 1985). Most of the work to date has involved axisymmetric jets at high Reynolds number with application to reducing jet engine exhaust noise, directing engine thrust, and reducing the infrared signature of a jet engine. Very little work has been done on the excitation of planar jets at moderate Reynolds numbers of about 6000 .

In our experimental setup we introduced periodic oscillations to the air flow, the details of which are beyond the scope of this paper. The purpose here is to examine the effect of this type of jet excitation on jet mixing.

\section{INFRARED IMAGING}

Historically, jet characteristics have been determined from a large number of poim measurements using instruments such as pitot tubes and hot-wire anemometry. Such sensors can provide detailed information about a particular point in a flow, but are tedious to use for characterizing overall flow characteristics. Jets, by their very nature, are dynamic and change with time. Entrainment is a process of vortex generation, engulfment of ambient fluid, and turbulent transport and dissipation of turbulent energy and momentum in the interior of the jet. Point sensors cannot provide an instantaneous view of the entire jet.

Imaging techniques provide a targe amount of data quickly, typically at 30 frames per second. The system described here has 256 columns by 200 rows or 51,200 pixels of information per frame. The data collection rate can exceed 1.5 million data points per second, although such a high rate is generally not required. The behavior of the entire jet can be studied dynamically.

The process of infrared imaging is discussed in more detail in Farrington and Hassani (1991). Radiant energy is in the infrared range with wavelengths between 8 and 12 microns. However, air is transparent to infrared radiation, with the exception of absorption and emission by water molecules. Therefore, a suitable emiting target is required to represent the air temperature. We used a fiber mesh screen with $0.25 \mathrm{~mm}$ $(0.01$-in.) diameter fibers and a porosity of $70 \%$. Cooled air flowed over the screen that was then be viewed with an infrared camera. The screen had a time response of $0.3 \mathrm{~s}$, which was sufficient to see rapid changes in the jet boundary but too low to see actual vortical structures (which have frequencies of hundreds of Hert $[\mathrm{Hz}])$.

Typical temperature differences between the jet outlet temperature and ambient temperature were $17^{\circ} \mathrm{C}$. Uncertainty of the temperature from the infrared system was on the order of $0.1{ }^{\circ} \mathrm{C}$ or about $0.6 \%$ of the maximum temperature span. Near the edge of the jet, the uncertainty of the temperature difference was about $6 \%$. By nondimensionalizing the temperature, we eliminated the effect of screen emissivity and the effect of uniform radiation from the surrounding walls in the room.

\section{EXPERIMENTAL SETUP}

The experimental setup is shown in Figure 1. The rectangular nozzle was $119 \mathrm{~cm}(47 \mathrm{in}$.) long with a slot width of $2.54 \mathrm{~cm}(1 \mathrm{in}$.). Air was provided by a squirrel cage blower located in an adjacent room along with a water-cooled chiller. Four screens and a set of turning vanes were placed uystream of the nozzle to condition the flow and provide a uniform, two-dimensional flow profile. The nozzle was placed so that air was directed vertically upward to minimize gravitational effects. The exit
Richardson's number based upon the nozzle width was 0.00103 , showing that buoyancy forces at the nozzle can be neglected compared with inertial forces. Because buoyancy forces could be neglected, the nozzle could be oriented down or up. We choose to mount the nozzle on the floor for good accessibility for measurements and modifications.

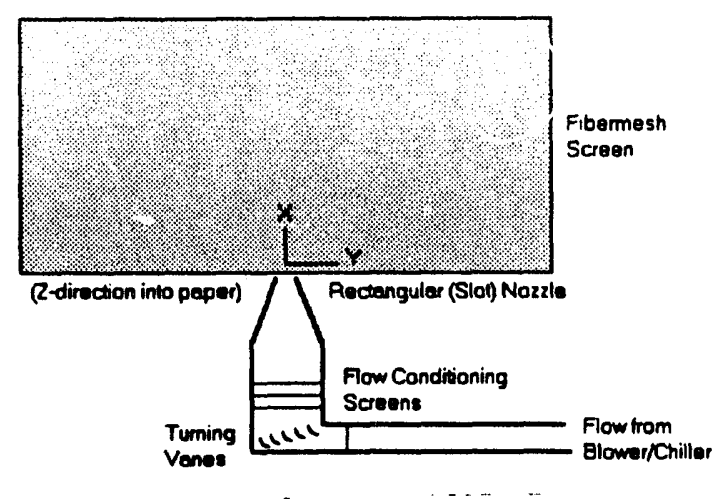

Figure 1. Schematic of Teat Loop (Not Drawn to Scalo)

The target screen was placed at the middle of the length of the nozzle for front viewing and along the centerline of the nozzle opening for side viewing. The camera viewing angle was perpendicular to the plane of the screen. Following standard notation for jets, the axial direction (following the main flow of the jet vertically upward) is labelled as $X$, the transverse direction (across the small dimension of the nozzle) $Y$, and the longitudinal direction (along the large dimension of the nozzle) $Z$.

\section{TEST RESULTS}

Althugh a wide range of excitation frequencies have been examined, only the results from one excitation frequency will be presented to demonstrate how infrared imaging characterizes jet behavior and shows the increased mixing from jet excitation. The results from 10 $\mathrm{Hz}$ excitation are representative of other excitation frequencies and are compared to the unexcited jet.

The key parameters used to analyze the jets were the minimum temperature of the jet, the jet edge, and the jet mixing efficiency. The edge. is defined in this paper as the position where the temperature difference between a point and the jet minimum temperature is $90 \%$ of the difference between the room temperature and the jet minimum temperature, all evaluated at a particular axial distance. The nondimensional temperature is defined as:

$$
\theta(x, y)=\frac{T(x, y)-T_{\text {Jet }}}{T_{\text {Ambieat }}-T_{\text {Jet }}}
$$

The nondimensional temperature ranges from 0 at the nozzle exit to 1 in the room.

The mixing efficiency is defined as the integral of the nondimensional temperature between the jet edges:

$$
\eta=\int_{-Y_{\infty \alpha \infty}}^{+Y_{\infty}} \int_{0}^{X} \theta(x, y) d x d y
$$


Infrared Images

Figures 2 and 3 show black-and-white representations of the infrared images of the front view of the jet. Figure 2 is at $0 \mathrm{~Hz}$ and Figure 3 at $10 \mathrm{~Hz}$ excitation. The corresponding nondimensional isotherms are shown in Figures 4 and 5, where the vertical and horizontal distances have been nondimensionalized by the nozzle width. $W$. The infrared images show the increased mixing of the excited jet that is indicated by the increased spreading of the jet immediately after exiting the nozzle and the decreased throw of the excited jet.
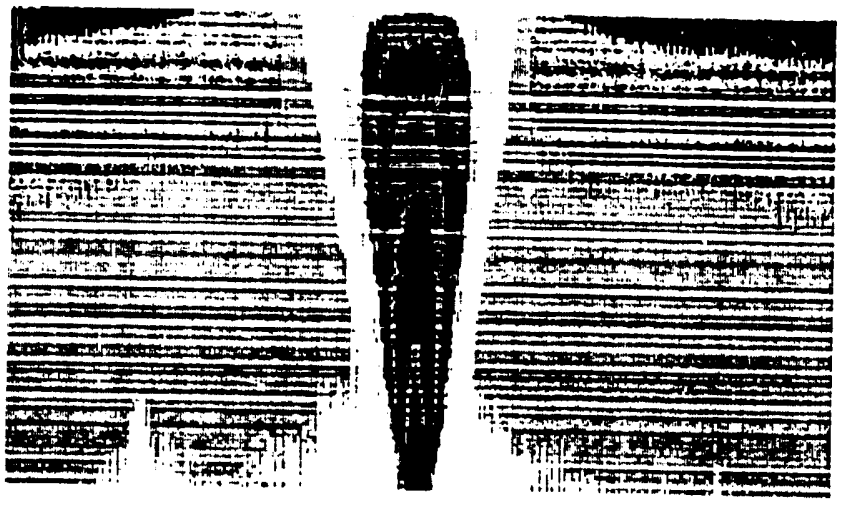

Figure 2. Infrared image, Front Vbow, 0 Hz, 200 setm
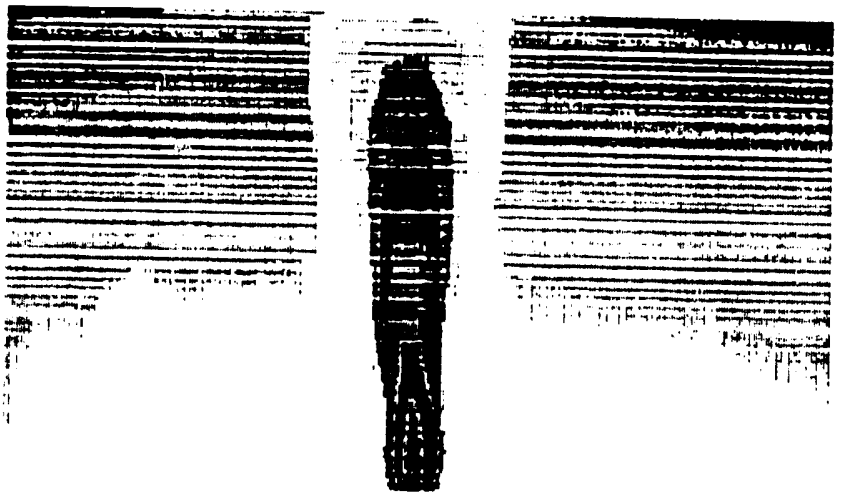

Figure 3. Infrared Image, Front View, $10 \mathrm{~Hz}, 200 \mathrm{scfm}$

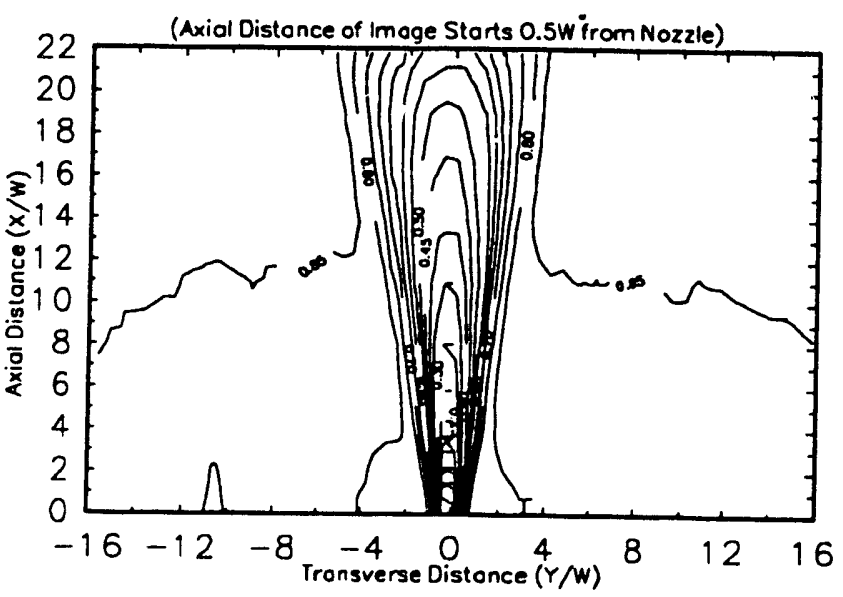

Figure 4. Nondimensional Jet lsotherms 0 Hz, $200 \mathrm{scfm}$

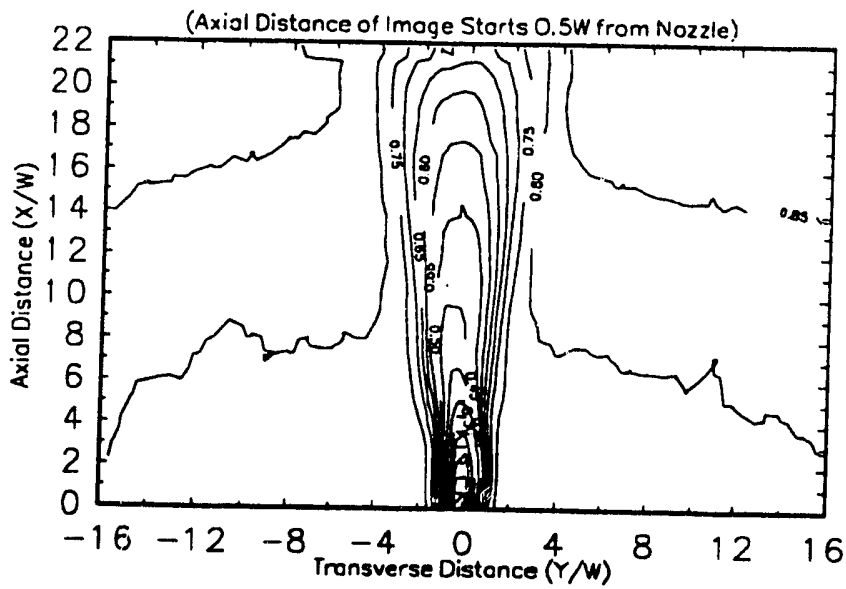

Figure 5. Nondimensional Jet lsotherms $10 \mathrm{~Hz}, 200 \mathrm{sctm}$

Infrared images taken of the side of the jet are shown in Figures 6 and 7 with their respective isotherms in Figures 8 and 9. The effect of excitation is seen as warm ambient air is drawn into the jet. Unlike the front view, where both the unexcited and excited tests were done at 200 standard $\mathrm{cfm}(\mathrm{scfm})$, the side view was done without changing the flow rate from the unexcited case. Therefore, the actual flow rate at $10 \mathrm{~Hz}$ excitation was $178 \mathrm{scfm}$ for the side view; the reduction in flow being caused by the excitation mechanism.

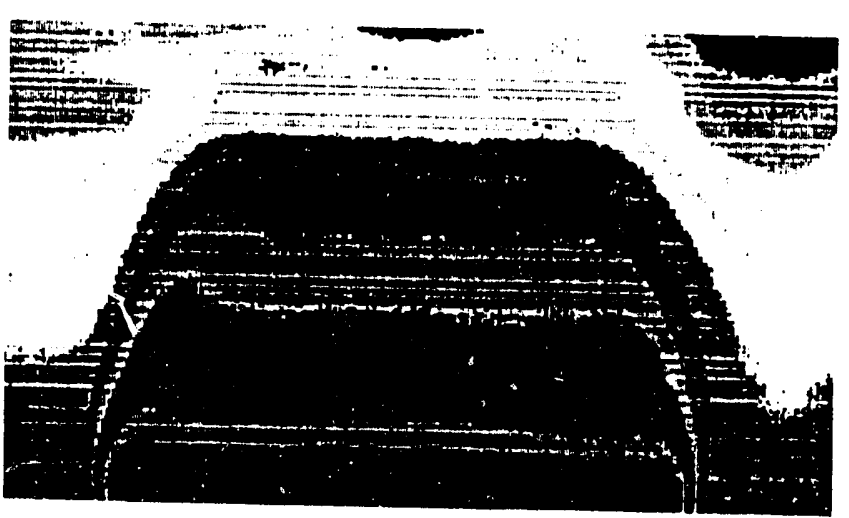

Figure 6. Infrared Image, Side View, $0 \mathrm{~Hz}, 200$ setm

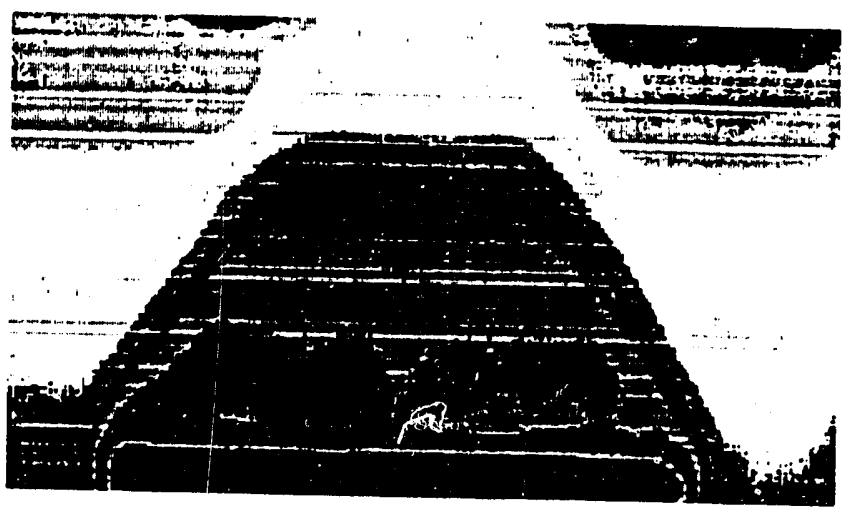

Flgure 7. Infrared Image, Side Viow, $10 \mathrm{~Hz}, 200 \mathrm{sefm}$ (Bofore
Excitation) 


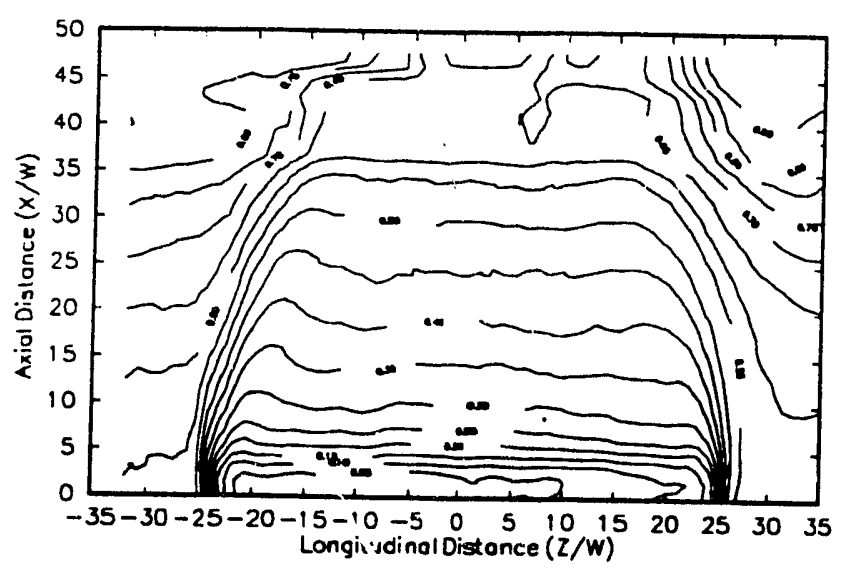

Figure 8. Nondimonalonal Jet tsotherms, Sids View 0 Hz, 200 sctm

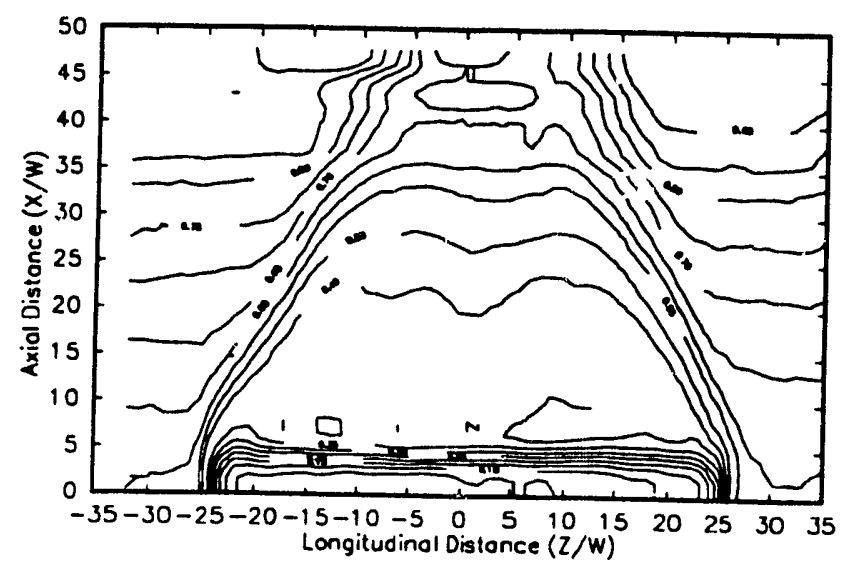

Figure 9. Nondimensional Jet lsotherms, side Viow $10 \mathrm{~Hz}, 200 \mathrm{sefm}$ (Bofore Excitation)

\section{Effect of Data Averaging}

The images shown in Figures 2 through 9 were done with averaged data. The infrared image contains over 50,000 data points, which are beyond the ability of most personal computers for contour plotting. Therefore, the data was processed using a nine-point averaging technique resulting in about 6000 data points. A comparison of the averaged results and the full data set follows.

Figure 10 shows a composite contour plot using all of the data points between -4 and +4 nozzle widths on the horizontal scale. The results compare very well with the contour plot of the averaged data shown in Figure 4. A comparison of the edge detection in Figure 11 also shows good agreement. The "stair-stepping" of the averaged data reflects the distance between the averaged data points of $0.258 \mathrm{Y} / \mathrm{W}$ horizontally which is $0.8 \%$ of the total width. However, to show detail, only one-quarter of the image width is shown in Figure 11. The axial distance between points was $0.373 \mathrm{X} / \mathrm{W}$ or $1.7 \%$ of the total height. Figures 12 and 13 compare the image minimum temperature and thermal mixing efficiency for the averaged and full data sets. Once again, good agreement is obtained.

The advantage of digital averaging is being able to manipulate smaller, more manageable data files on a personal computer. Data can be reduced more quickly than processing the entire data file.

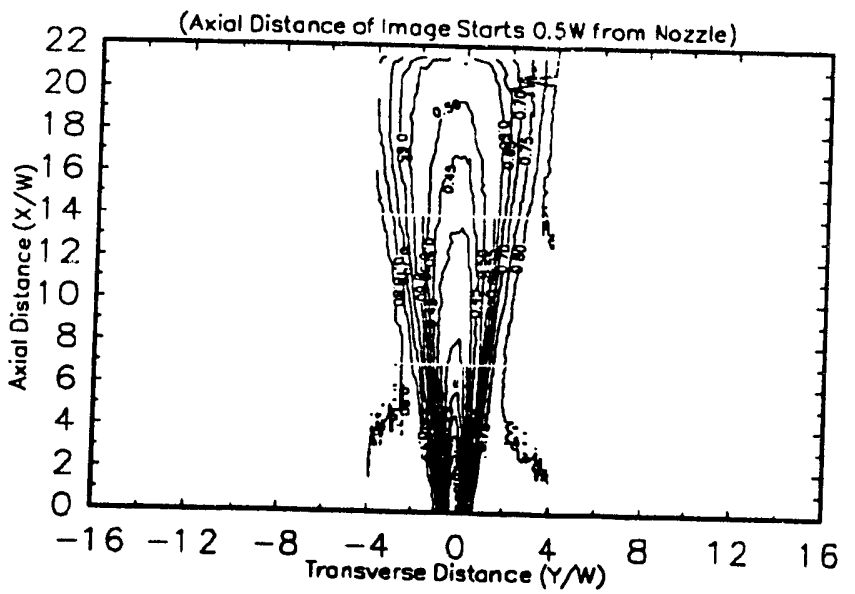

Figure 10. Nondimensional Jet lsotherms, Full Date sot $0 \mathrm{~Hz}$,

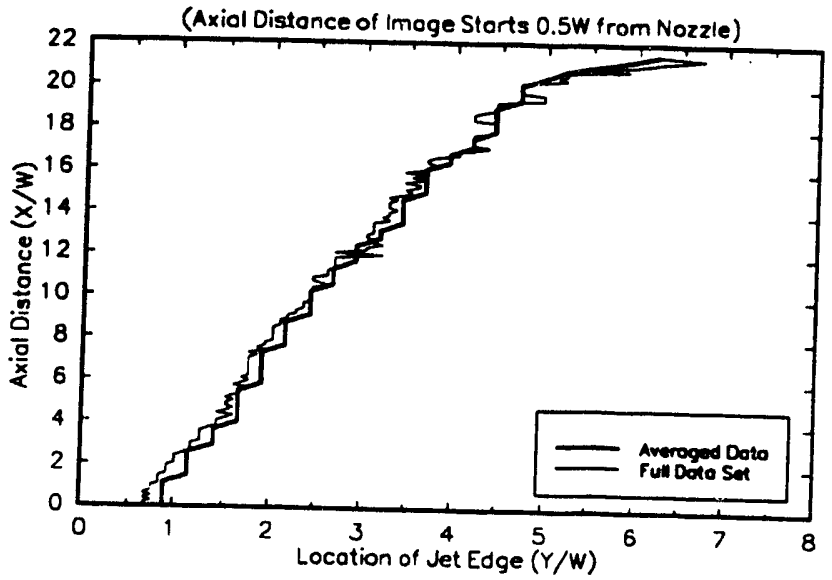

Figure 11. Comparison of Full and Averaged Data Sots Right Edge of Jet $0 \mathrm{~Hz}, 200 \mathrm{sefm}$

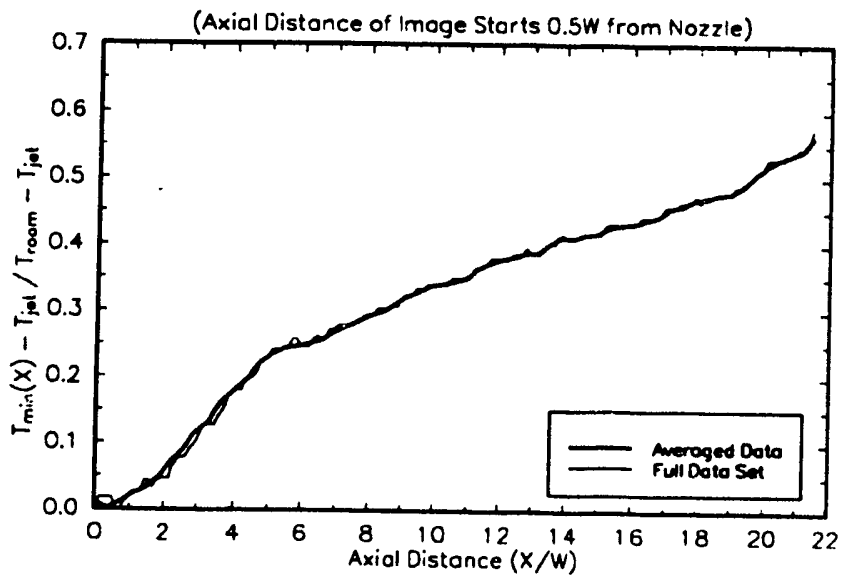

Figure 12. Comparison of Full and Averaged Data Suts Jot Minimum Temperature $0 \mathrm{~Hz}, 200$ scfm 


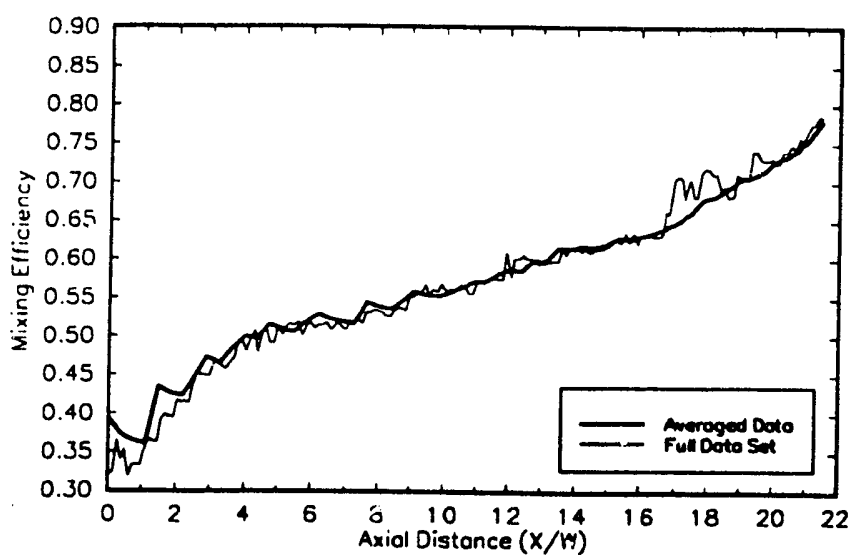

Figure 13. Comparison of Full and Averaged Date Sets Axial Thermal Mixing Efficiency $0 \mathrm{~Hz}, 200 \mathrm{sctm}$

\section{Repeatability}

Jets move dynamically; therefore, it is important that results properly characterize jet behavior. The front images are composites of 120 images, each consisting of two frame averages, taken every second. The mean behavior of the jet should be constant. The temperature contour plot in Figure 14 is taken 1 hour after the test shown in Figure 4. During this time the air temperature at the nozzle exit had increased $1.9^{\circ} \mathrm{C}$ and the room temperature $0.7^{\circ} \mathrm{C}$. The nondimensional isotherms in Figures 4 and 14 compare very well. Figures 15, 16, and 17 show comparisons of the jet edge, jet minimum temperature, and thermal mixing efficiency. Once again, excellent agreement is obtained showing that the results are representative of jet behavior.

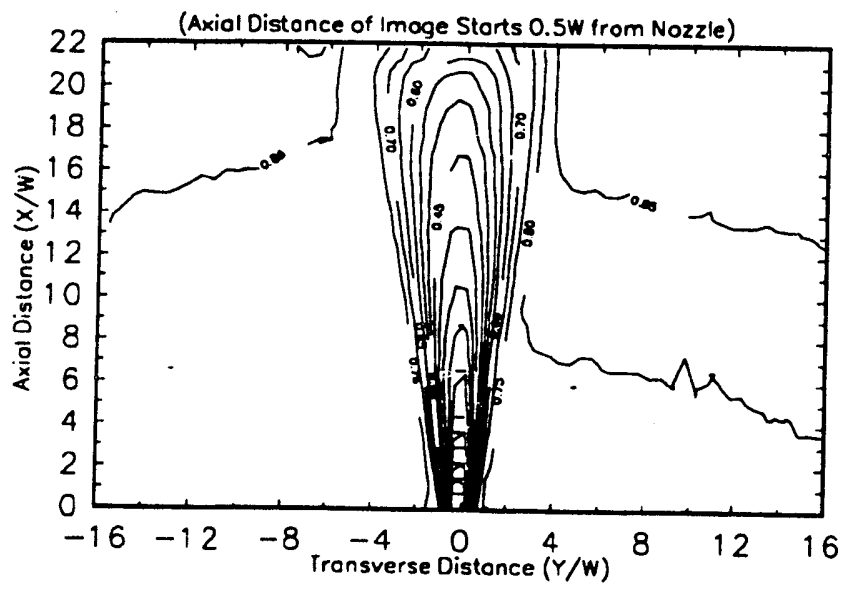

Figure 14. Nondimonsional Jet Isotherms, Repeated Test $\mathrm{O}$ Hz, $200 \mathrm{~cm}$

\section{Effect of Excitation}

The effect of jet excitation can be observed in a number of ways. First, by comparing Figures 2 and 3 and Figures 4 and 5 , we see the shape of the jet has changed, particularly near the nozzle. The jet spreads quicker near the nozzle, and the penetration of cold air is shortened. This can be further confirmed by detecting the edges of the jet as shown in Figure 18.

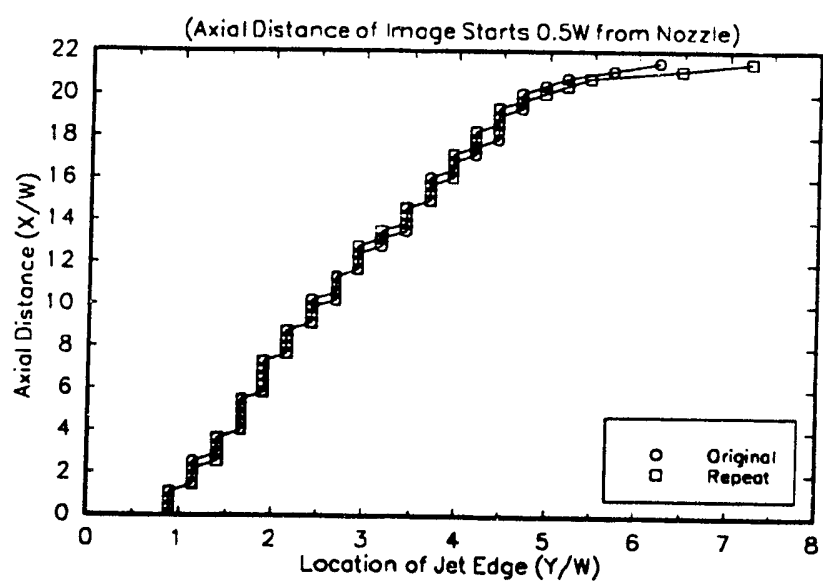

Figure 15. Repaatability Test, Right Edge of Jot $0 \mathrm{~Hz}, 200 \mathrm{sctm}$

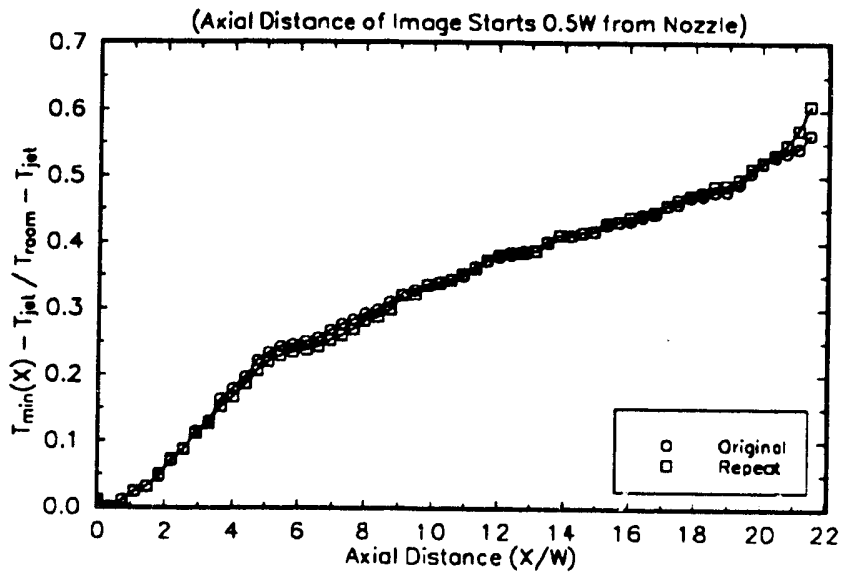

Figure 16. Repeatability Test, Jet Minimum Temperature $0 \mathrm{~Hz}$, $200 \mathrm{ctm}$

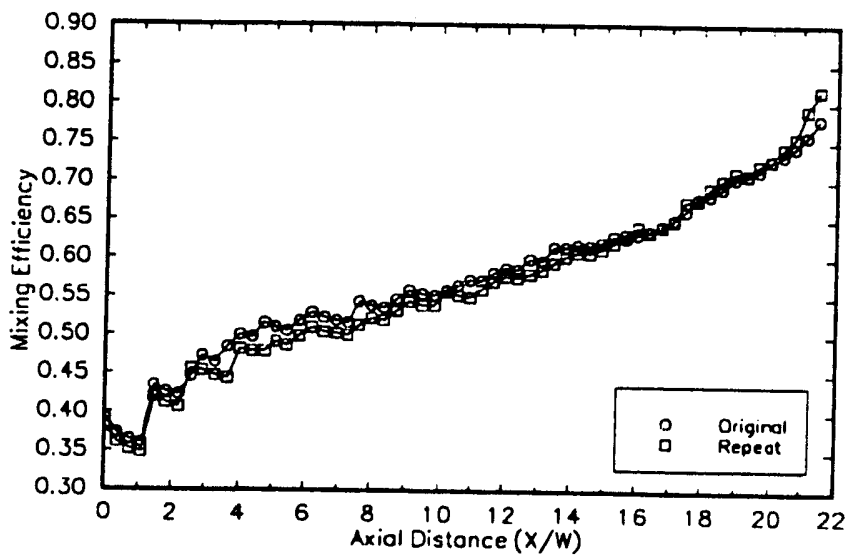

Figure 17. Repeatability Test, Axial Thermal Mixing Efficiency $\mathrm{O} \mathrm{Hz}$, 200 scfm 


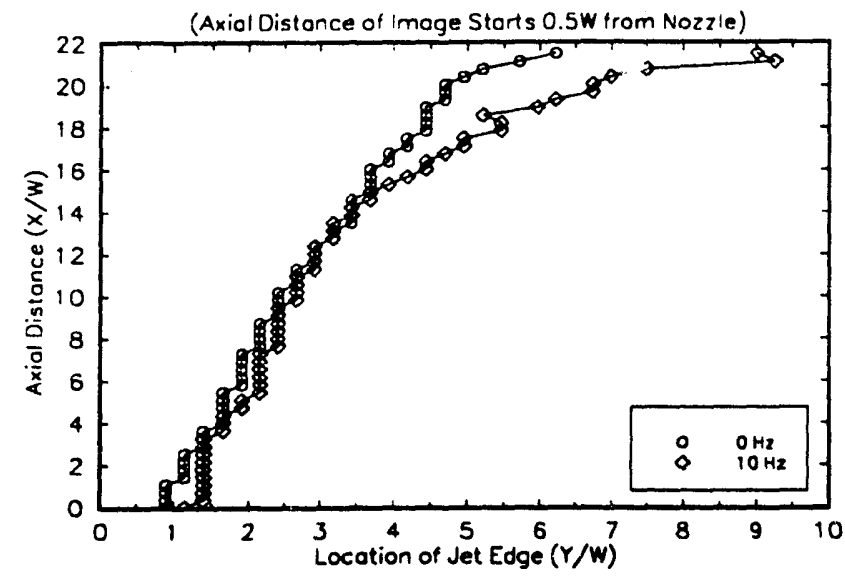

Figure 18. Effect of Jat Excitation on Right Edge of Jet 0 and $10 \mathrm{~Hz}$, 200 sefm

The thermal centerline of the jet is represented by the minimum temperature in the jet cross-section. Increased mixing would lead to warmer temperatures in a cold jet, as shown in Figure 19. Within five nozzle diameters, the excited jet is significantly warmer than the unexcited jet. Further along the axial direction, both jets completely mix with the room air.

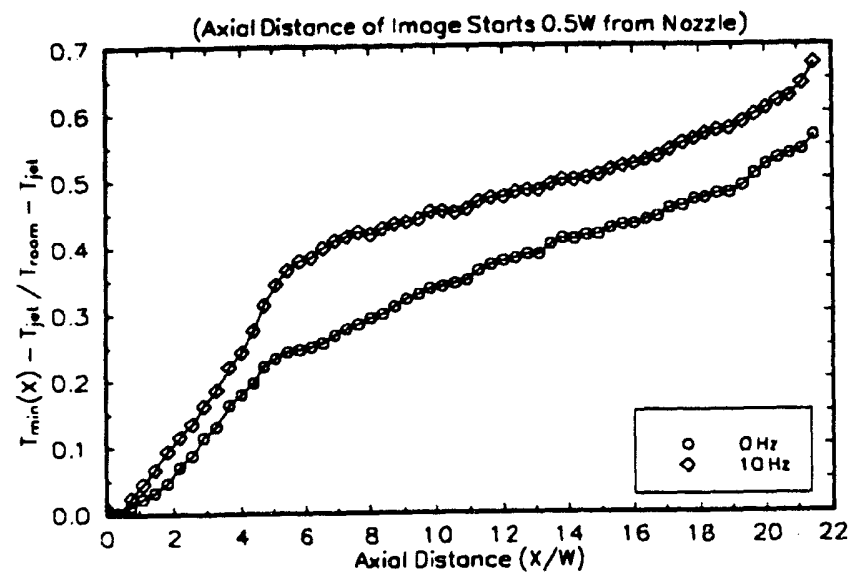

Floure 19. Efrect of Jet Excitation on Jet Minimum Temperature 0 and $10 \mathrm{~Hz}, 200 \mathrm{setm}$

Mass flow entrainment is a measure of the amount of ambient mass brought into the jet and requires a knowledge of the velocity profile of the jet. However, the velocity profile is not readily available from this infrared technique. Therefore, a thermal mixing efficiency was defined above that was related to the entrainment ratio. The mixing efficiency was determined from the temperature distribution in the jet. Temperature is a scalar and can be used as a passive tracer in a flow, as long as the temperarure difference is small enough not to affect the buoyancy of the flow. Thermal diffusion on a molecular level is much smaller than turbulent thermal diffusion as is the case for other tracers used for flow visualization. Therefore, thermal diffusion can be neglected. The temperature profile (like flow visualization using tracers) provides insight into the jet characteristics but is different than the velocity profile. Turbulent mass transport is greater than momentum transport in turbulent jets resulting in greater spreading of mass (and temperature) than of velocity. Figure 20 shows increased mixing of the excited jet as a function of the axial position. The overall jet mixing efficiency was 0.62 for the unexcited jet and 0.69 for the excited jet showing about an $11 \%$ increase in jet mixing over an axial distance of 22 nozzle widths.

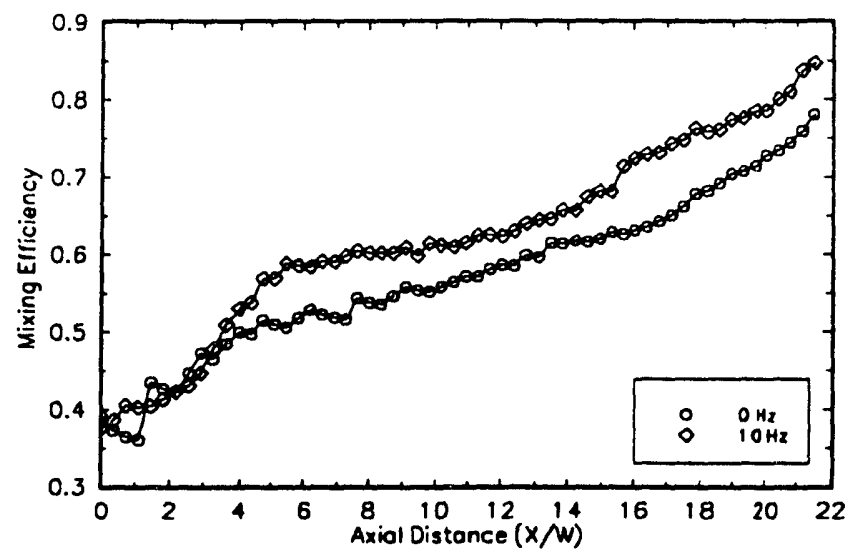

Figure 20. Effect of Jet Excitation on Axial Thermal Mixing Efficioncy $O$ and $10 \mathrm{~Hz}, 200 \mathrm{sefm}$

\section{CONCLUSIONS AND RECOMMENDATIONS}

This work has two major conclusions: one concerns the measurement process and the other concerns the object of the measurements. The process of using infrared imaging and digital analysis has been used successfully to study jet behavior. Averaged data sets can be used to represent full infrared images, and the results are repeatable. The application of infrared imaging to jet excitation at low frequencies has shown that excitation increases jet mixing. In the plane jet tested, an $11 \%$ increase in jet mixing was observed at an excitation frequency of 10 Hz. Increased jet mixing should lead to better room air distribution, lower energy costs, better air quality, and high levels of occupant comfort.

Testing over a range of excitation frequencies and flow rates is in progress. The infrared results will be compared with jet edges, axial velocity decay, and entrainment ratios obtained from hot-wire anemometry testing. The results will show jet mixing efficiency as a function of jet excitation frequency. Comparison between the infrared results and the hot-wire anemometry results will also provide information on the effect of the screen on the flow. This work will be expanded to wall jets, which are commonly used in delivering air to rooms.

\section{ACKNOWLEDGMENTS}

The development of the infirared imaging system was funded by the U.S. Department of Energy, Office of Building Technology. John Talbort, Program Manager. The testing of excited jets used for advanced diffuser development was funded by the National Renewable Energy Laboratory Director's Development Fund.

\section{REFERENCES}

ASA, 1946, ASA Standard AS3.1 Light and Ventilation. American Standards Association, New York, NY. 
ASHRAE, 1973, ASHRAE Standard 62-1973, Standards for Natural and Mechanical Ventilation, American Society of Heating, Refrigerating and Air-Conditioning Engineers, Atlanta, GA.

ASHRAE, 1981, ASHRAE Standard 62-1981, Ventilation for Acceptable Indoor Air Quality, American Society of Heating, Refrigerating and Air-Conditioning Engineers, Allanta, GA.

ASHRAE, 1989, ASHRAE Standard 62-1989. Ventilation for Acceptable Indoor Air Quality, American Society of Heating, Refrigerating and Air-Conditioning Engineers, Atlanta, GA.

ASHRAE, 1991, IAQ '9? Healthy Buildings, American Society of Heating, Refrigerating and Air-Conditioning Engineers, Atlanta, GA.

ASTM, 1989, Design and Prorocol for Monitoring Indoor Air Quality, American Society for Testing and Materials, Philadelptia, PA.

EPRI, 1990, Proceedings: Ventilation Workshop, Volumes 1 and 2, Electric Power Research institute, Palo Alto, CA.

Fanger, P., 1988, "A Comfort Equation for Indoor Air Quality and Ventilation," Healthy Buildings '68, Vol. 1, State of the Art Reviews, Swedish Council for Building Research, Stockholm, Sweden, pp. 39-51.

Farrington, R., and V. Hassani, 1991, "Use of Infrared Imaging to Determine the Mixing Performance of Supply Air Diffusers," IAQ 9 I Healthy Buildings, American Society of Heiding, Refrigerating and Air-Conditioning Engineers, and the International Council for Building Research, Studies and Documentation, ASHRAE, Atlanta, GA, pp. 179-185.

Farrington, R., D. Martin, and R. Anderson, 1990, "A Comparison of Displacement Efficiency, Decay Time Constant, and Age of Air for Isothermal Fl w in an Imperfectly Mixed Enclosure," ACEEE 1990 Summer Study on Energy Efficiency in Buildings - Environment, American Council for an Fnergy-Efficient Economy, pp. 4.35-4.43.
Koestel, A., 1955, "Paths of Horizontally Projected Heated and Chilled Air Jets, ASHRAE Transactions, American Society of Heating, Refrigerating and Air-Conditioning Engineers, Atlanta, GA, Vol. 61, pp. 213-232.

LeConte, J., 1858, "On the Influence of Musical Sounds on the Flame of a Jet of Coal-Gas," The London, Edinburgh and Dublin Philosophical Magazine and Joumal of Science, Fourth Series XV, pg. 235-239

McNall, P., and K. Teichman, 1988, "Indoor air Quality Standards and Codes in the United States," Healthy Buildings '88, Volume I State of the Art Reviews, B. Berglund and T. Lindvall, ed., Swedish Council for Building Research, Stockholm, Sweden, pp. 163-168.

Miller, P., 1979, "Design of Room Air Diffusion Systems Using the Air Diffusion Performance Index (ADPI)," ASHRAE Journal, American Society of Heating, Refrigerating and Air-Conditioning Engineers, Atlanta, GA, October 1979, pg. 85.

Reynolds, W. C., and M. Lee, 1985, "Bifurcating and Blooming Jets," Technical Report TF-22, Stanford University, Stanford, CA.

Tyndall, J., 1867, "On the Action of Sonorous Vibrations on Gaseous and Liquid Jets," The London, Edinburgh and Dublin Philosophical Magazine and Joumal of Science, Fourth Series XXXIII, pg. 375-391.

University of Illinois, 1988, Building Systems: Root Air and Air Contaminant Distribution, University of Illinois, ChampaignUrbana, IL. 

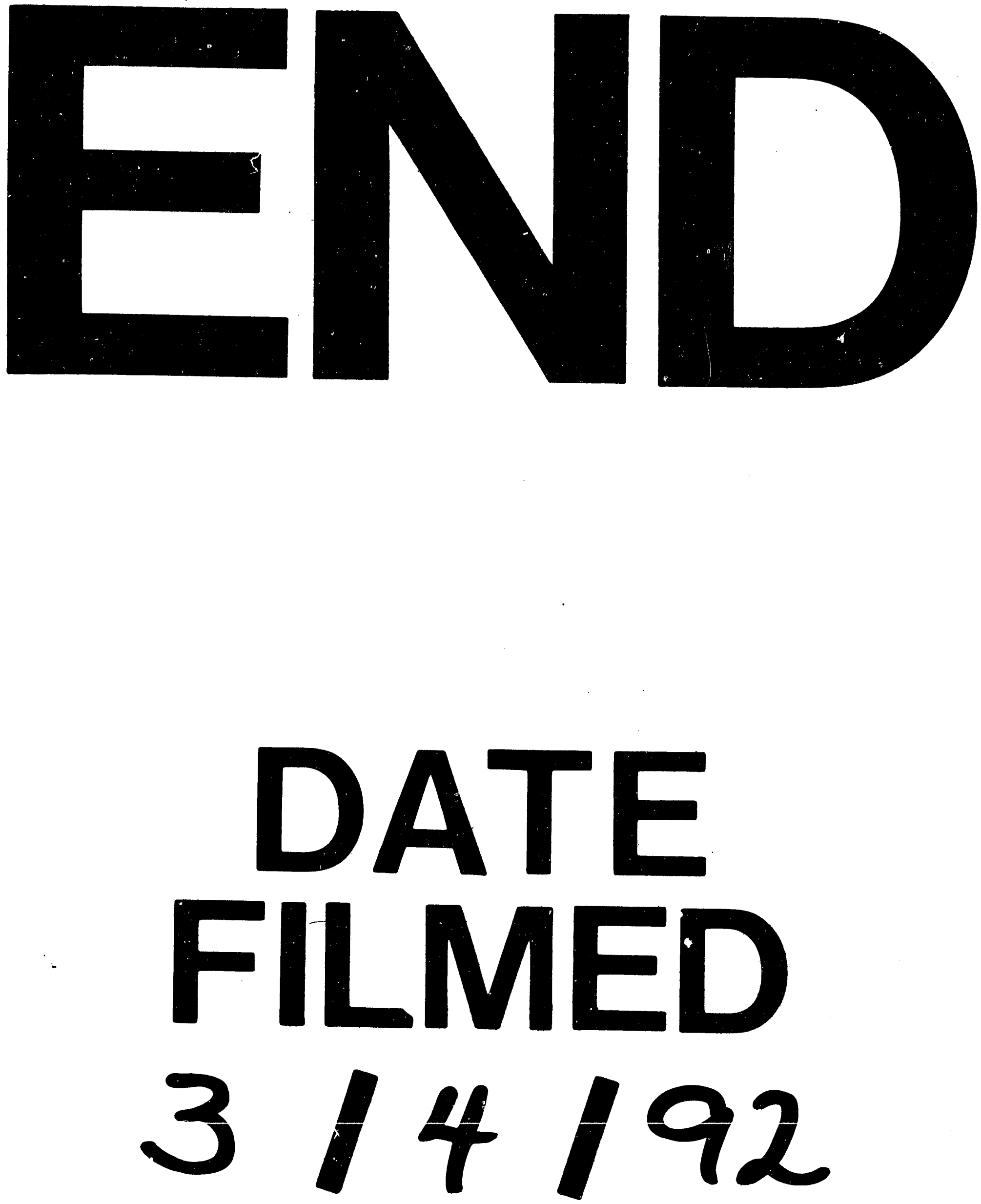
